\title{
Genetic analysis of adult locomotor activity in Drosophila melanogaster
}

\author{
R. Costa, $\dagger$ \\ L. A. Zonta, $\ddagger$ \\ M. Osti, $†$ and \\ S. D. Jayakar $\ddagger^{*}$
}

\author{
$\uparrow$ Department of Biology, University of Padova, \\ Via Trieste 75, 35121 Padova, Itally. \\ ‡ Department of Genetics and Microbiology, \\ University of Pavia, Via S. Epifanio 14, \\ 27100 Pavia, Italy.
}

This study is an attempt to identify genes influencing spontaneous adult locomotor activity in Drosophila melanogaster. A wild type stock and 13 morphological marker stocks (six markers for chromosome $\mathrm{X}$ and seven for chromosome three have been used). Backcrosses have been set up to study linkage relationships between loci affecting the quantitative character and marker loci. The results suggest the presence of several genes influencing locomotor activity on both chromosomes analyzed.

\section{INTRODUCTION}

Both theoretical (Beckmann and Soller, 1983; Chotai, 1984; Weller, 1986) and experimental studies (Maroni et al., 1982; Tanksley et al., 1982; Vallejos and Tanksley, 1983; Schnee and Thomson Jr., 1984; Weller, 1987; Shrimpton and Robertson, $1988 a ; 1988 b)$ concerning the detection and mapping of genes influencing quantitative characters seem to represent a renewed interest in the field of quantitative genetics. This is probably mainly due to the fact that in many economically important organisms a number of commercial traits are quantitative variables, as in the case of Lycopersicon (tomato), for which 22 loci affecting quantitative characters, for example $p \mathrm{H}$, vitamin $\mathrm{C}$ concentration, reducible sugar concentration, etc., have been mapped (Weller 1987; Weller et al., 1988). Thompson Jr. and Thoday (1979) reviewed the most important methods proposed for the location of genes influencing quantitative traits: almost all the approaches make use of the selection of lines that differ strongly for the character under study. Jayakar (1970) and Jayakar et al., (1977), starting from Thoday's approach $(1961 ; 1966)$ based on the detection of linkage between genetic markers and loci affecting quantitative traits, suggested an experimental and statistical methodology useful for any population of diploid organisms. A considerable advantage of Jayakar's

* Deceased 21.1.1988. approach is that it does not need to select lines for high or low values of the quantitative trait, but analyzes the distribution of the trait among the individuals of the segregating classes obtained from either backcrosses or intercrosses for a marker locus, situations which can be observed in nature besides being easy experiments to set up in the laboratory.

The quantitative character here studied is adult locomotor activity in Drosophila melanogaster, which has been the object of several investigations (Connolly, 1966; 1967; Angus, 1974; Burnet and Connolly, 1974; van Dijken et al., 1977; 1979; van Dijken and Scharloo, 1979a, b; Kyriacou, 1981; Le Bourg et al., 1984; Le Bourg and Lints, 1984; Lints et al., 1984; 1985; Meehan and Wilson, 1987; Burnet et al., 1988; O'Dell and Burnet, 1988). This is a complex behavioural trait for which significant levels of heritability have been generally demonstrated (Ewing, 1963; Connolly, 1966; Angus, 1974; van Dijken and Scharloo, 1979a), even if in one case no response to selection experiments was obtained (Lints et al., 1985). The activity of $D$. melanogaster was first subdivided into two components, "spontaneous activity" and "reactivity" (Burnet and Connolly, 1974); more recently a third, distinct, category has been defined and named "stimulated activity" (Mehan and Wilson, 1987). Moreover the locomotor activity of single flies, as revealed by "open-field" observations, is characterized by two different behavioural components, the "amount" and "speed" of movement 
a)

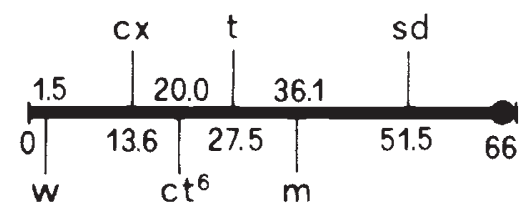

b)

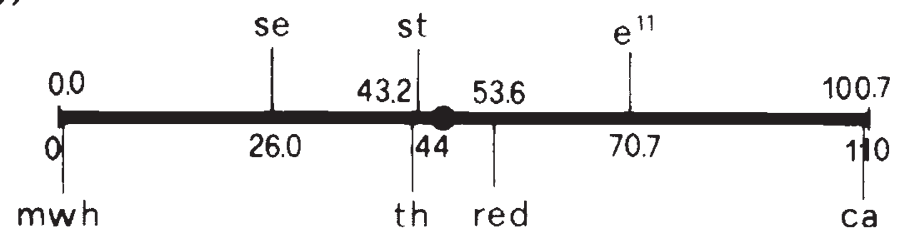

Figure 1 Genetic map of the morphological markers used in the experiments. a, chromosome X; $b$, chromosome 3.

(Burnet et al., 1988). Sex differences in locomotor activity have been described, females being often more active than males, and also the decrease of activity with increasing age in both sexes (Le Bourg and Lints, 1984). Lack of correlation between spontaneous locomotor activity and fecundity, fertility and lifespan has also been reported for females from a wild laboratory strain (Le Bourg et al., 1984).

A genetic analysis of locomotor activity in $D$. melanogster has been made by van Dijken et al. (1979) on three pairs of high and low locomotor activity lines obtained independently from two different base populations. The results of experiments using reciprocal crosses as well as chromosome substitutions suggested that a considerable part of activity differences was attributable to the effects of chromsome X. Minor effects were due to the second and third chromosomes; moreover significant interactions between chromosomes were also reported. Vaj and Jayakar (1976) in a study aimed to assess the importance of autosomal genes in the determination of locomotor activity in $D$. melanogaster have found that chromosome 4 is the most influential in controlling this character.

Burnet et al. (1988) commenting on the results obtained by Connolly $(1966,1967)$ argued that spontaneous activity and reactivity are probably under control of different genetic systems. The same authors also suggested that the amount and speed components of locomotion are affected by different genes, that those influencing the amount of locomotion are located on chromosome 3 , and those responsible for speed on chromosome $\mathrm{X}$ and
2. Of course this does not exclude the existence of genes which could affect both the components. It is even likely that larval and adult locomotor activities be under control of different genes, because of lack of correlation between them (Sewell et al., 1975; Thompson Jr. et al., 1983; Burnet et al., 1988). In this paper we analyze the genetical effects on adult locomotor activity of chromosomes X and 3 in D. melanogaster according to Jayakar's model $(1970 ; 1977)$ extended to the case of sex-linked genes. To this purpose a total of 13 morphological markers have been utilized.

\section{MATERIAL AND METHODS}

\section{Stocks and morphological markers}

The wild-type stock (Cast-PD), used as a random source of individuals to study locomotor activity, was established in 1984 from a large sample collected in the wild in the neighbourhood of Padua (Italy). The morphological markers used in the experiments are shown in fig. $1 . w, c x, c t^{6}, m, s e$, $t h$, and $e^{11}$ stocks were kept in our laboratory collections in homozygous condition. The other markers were obtained: red and $s t$ from Professor M. Gatti (Rome), sd from Professor S. Cavicchi (Bologna), $m w h$ from Professor Wurgler (Zurich), $t$ and $c a, K-p n$ from the Umea Drosophila stock center. The stock $c a, K$-pn was used considering that no phenotypic effects are shown by $K$-pn either in homozygous or heterozygous conditions if $p n$ $(1-0 \cdot 8)$ is not present. The stocks were carefully checked before use with respect to their phenotypic 
a)

CONTROL

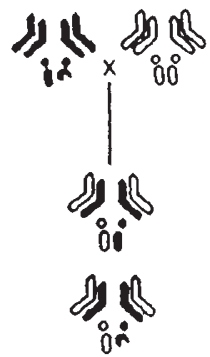

b)

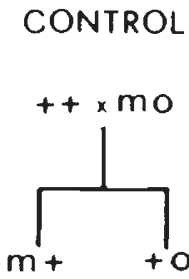

BACKCROSS

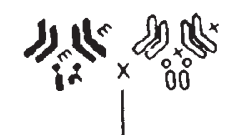

CONTROL

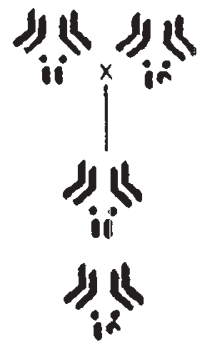

Figure 2 Scheme of the experimental design: backcrosses and control crosses with the wild type (vite) and an autosomal marker (black) stocks (a). A simplified scheme for an X-linked marker is also shown (b).

characteristics according to Lindsley and Grell (1972).

Individual crosses were set up with 1-2 day old individuals, cultured at $24^{\circ} \mathrm{C} \pm 1^{\circ} \mathrm{C}$ on a sucroseyeast medium (Mittler and Bennet, 1962).

\section{Experimental design}

The experimental schemes adopted are shown in fig. 2. Only backcrosses with heterozygous females were used because of the lack of crossing-over in Drosophila male. For each marker, from a minimum of 9 to a maximum of 16 backcrosses were set up.

Individuals to be measured were randomly chosen from each control and backcross sibship, males and females approximately in equal number, unless the sibship size was small and therefore all the emerged flies were tested. As for $t$ marker, only females were scored for the sake of accuracy in classifying the phenotypes.

\section{Measurement of locomotor activity}

Individuals were tested for locomotor activity 48 54 hrs after eclosion. No significant differences were observed within each control (and also within each backcross) in the mean scores of groups of flies examined on different days. Flies to be measured were transferred to fresh food vials, and scored always in the afternoon (between 1300 and $1800 \mathrm{~h}$ ) under constant light (tungsten lamp11.9 Watts $\left.\times \mathrm{m}^{-2}\right)$ and temperature $\left(24^{\circ} \mathrm{C}+1^{\circ} \mathrm{C}\right)$ conditions. The locomotor activity score of a fly is its total walk-measured in degrees-during 90 seconds inside a horizontal glass tube (internal diameter $=3 \mathrm{~mm}$ ) shaped as a $10 \mathrm{~cm}$ diameter ring. Similar apparatus had been used in previous studies by Connolly (1966) and by Vaj and Jayakar (1976). Flies were brought into the ring after weak anaesthesia with $\mathrm{CO}_{2}$ and tested for locomotor activity after 15 minutes to reduce effects due to the "reactivity" component (Burnet et al., 1988). In order to eliminate any possible influence on 
locomotor behaviour due to chemical cues released by the flies, a battery of glass rings was used and the rings were systematically cleaned. In the experiments carried out with $t h, w, c t^{6}, s d$ morphological markers, control and backcross progeny was scored, in addition to locomotor activity, also for thorax-abdomen length by using a microscope equipped with a micrometer ocular. The same survey was done in a sample of the wild stock "Cast-PD".

\section{Statistical analyses}

Statistical analyses have been carried out on the locomotor activity scores of the offspring of the control crosses, in the two sexes separately.

The square root transformation has been applied to the data in order to normalize the four frequency distributions (two genotypes $\times$ two sexes) of the values obtained for each of the six $\mathrm{X}$-linked and the seven autosomal markers. Even if this transformation turned out to be better than the others, like the log transformation, suggested by the form of the distributions, in a few cases the distributions departed significantly from normality in spite of the transformation applied. We have then resorted to nonparametric methods to com- pare them. The distributions have been graphically described by Tukey's box-and-whiskers representation (Tukey, 1977), and have been compared, between sexes and between genotypes, by Mann-Whitney U-test.

The analyses performed for the detection of linkage are based upon the model developed by Jayakar (1970) for one autosomal di-allelic locus influencing the quantitative trait and a di-allelic marker locus. However, it can be easily shown that the model is valid for X-linked genes in either sex, if appropriately modified to take into account the mode of inheritance of sex-linked characters.

The assumptions made are that the frequency distribution of the quantitative character has different means but equal variances in the three genotypes of the "quantitative" gene, the distributions being normal. The variance within genotype, besides the environmental component, includes a component of variability due to the rest of the genome. The same model has been adopted also by Hill (1975).

A complete theoretical analysis of all possible backcross families of the marker locus and their progeny shows that, in the presence of linkage, the mean value of the trait is expected to be different in the two segregating classes of those families in which a proportion $r$ of the offspring is derived

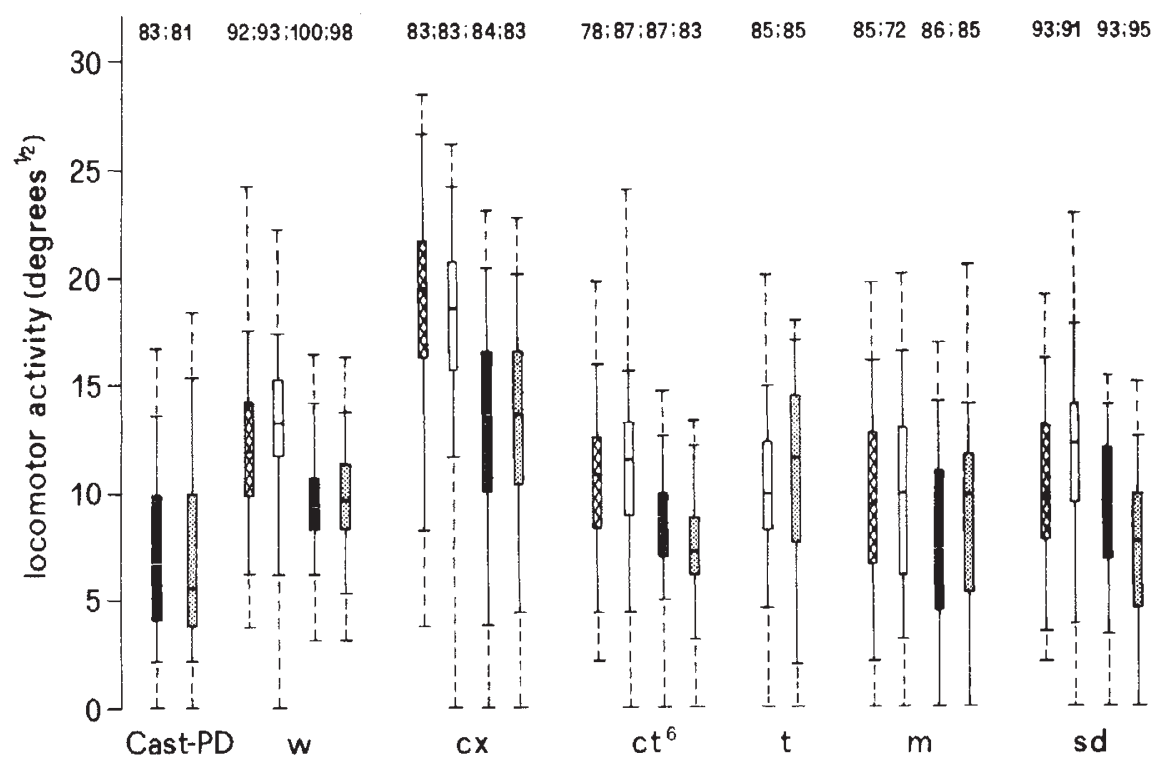

Figure 3 Box-and-whiskers representation of the distributions of locomotor activity scores in the offspring of control crosses for the wild type and the X-linked marker stocks. For each distribution, besides the lowest and the highest values, the 5th, 25th, 50th, 75th and 95th percentiles are indicated. The sample size is also given. $m+$ females, $m m$ (or wild type) females. See also legend to Table 1 . 


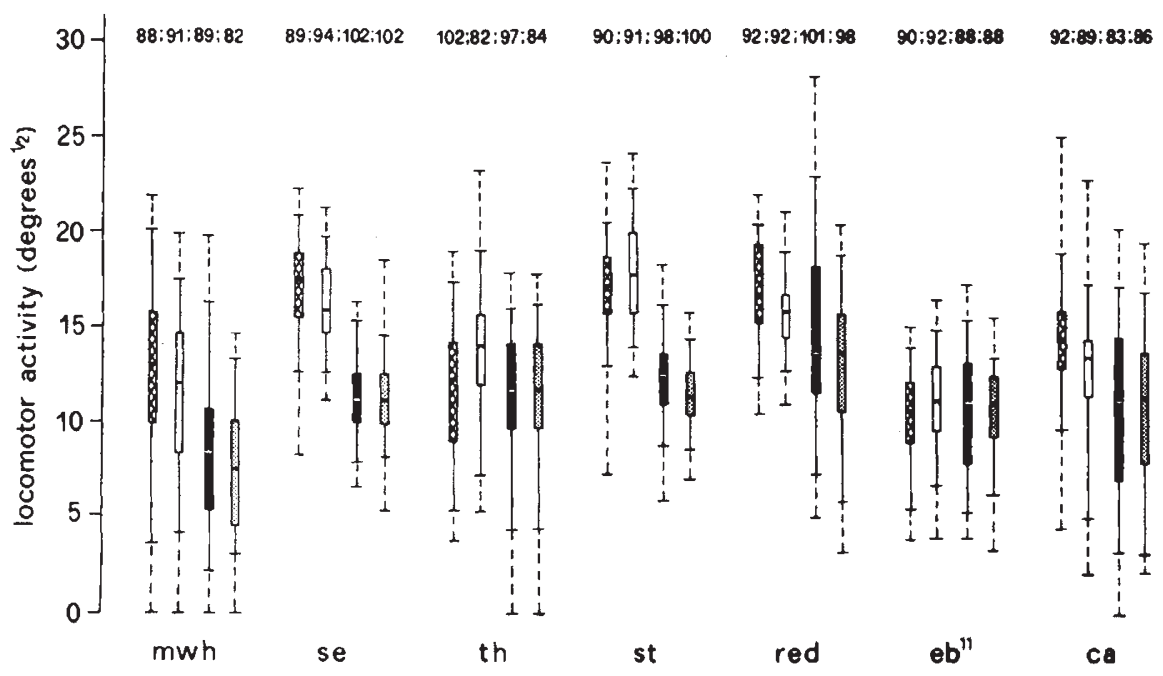

Figure 4 Chromosome 3 markers. See legend to figure 3. $m+$ males, $\square m+$ females, $m m$ males, $m m$ females.

from recombinant gametes. Therefore, while some families have identical means in the segregating classes independently of linkage, some do show differences which are a function of the recombination frequency (Jayakar, 1970). The probability of finding these informative sibships in a sample is determined by the allelic frequencies at the "quantitative" locus, with a maximum of 50 per cent of informative families when the two "quantitative" alleles are equifrequent. The first approach has been that of comparing the mean locomotor activity in the two segregating classes for all the families of the marker locus, by means of MannWhitney U-test.

Furthermore, for the detection and estimatioi of linkage we have applied the index $\left(I_{2}\right)$ derived by Jayakar and colleagues (Jayakar et al., 1977), which is based on the difference between the trait means of the two segregating classes within sibship. In fact, while the expected value of this difference over all sibships is zero, its variance among families is a function of the recombination frequency $r$ of the form var $=F_{1}+F_{2}(1-2 r)^{2}$, with a maximum value for $r=0$ and a minimum for $r=0 \cdot 5 . F_{1}$ and $F_{2}$ are constants which depend upon the parameters of the model. The estimate of this variance is quite complicated; however, the variance of the differences observed in the segregating classes of a sibship can be a useful approximation. The index $I_{2}$ is then computed as $I_{2}=\sum_{i=1}^{n}\left(x_{1}-x_{2}\right)^{2} /(n-1)$ where $x_{1}$ and $x_{2}$ indicate the trait means of the two segregating classes, and $n$ the number of families.

To avoid the influence of extreme values on the estimate of the mean in the segregating classes, the midmean has been used, that is the average of the values which are between the 1st and the $3 \mathrm{rd}$ quartiles. While it is not easy to assess the statistical significance of index $I_{2}$, it has the advantage to provide a linkage map when a battery of marker loci is used to explore a whole chromosome and only one "quantitative" gene is present on it: in fact since $I_{2}$ is a function of $1-2 r \quad(r=$ recombination frequency), it is expected to be maximum for the marker nearest to the "quantitative" gene and to decrease monotonically for markers farther away. It has to be remembered that some flaws in the map might occur, when by mere chance no informative family is included in the backcrosses of a marker.

\section{RESULTS}

\section{Controls}

A "box-and-whiskers" description of the distributions of locomotor activity scores in the controls is given in figs. 3 and 4 , separately for the two sexes and the genotypes at the marker locus, with the corresponding number of individuals tested. In figure 3 the information for the wild type stock Cast-PD has been included. A few individuals (1.12 per cent) show complete lack of activity: it has to be noted that this phenomenon is not present in all the stocks (see figures 3 and 4). On the whole, the distributions are quite different from one another with respect both to location and dispersion. In general, hybrids are more similar to the marker stock they are derived from than to the 
Table 1 Significance of Mann-Whitney U-test performed between sexes (MM males; FF females) and between genotypes among the offspring of the control crosses. + and $m$ refer to wild type and mutant allele respectively. 0 indicates the hemizygous condition for X-linked markers

\begin{tabular}{|c|c|c|c|c|}
\hline \multicolumn{5}{|c|}{ Chromosome $\mathrm{X}$} \\
\hline & +0 vs. $m 0$ & $+m$ vs. $m m$ & +0 vs. $+m$ & $m 0$ vs. $m m$ \\
\hline$w$ & $* * *$ & $* * *$ & * & ns \\
\hline$c x$ & $* * *$ & $* * *$ & ns & ns \\
\hline$c t^{6}$ & $* * *$ & $* * *$ & ns & $*$ \\
\hline$t$ & - & $*$ & - & - \\
\hline$m$ & $* *$ & ns & ns & * \\
\hline$s d$ & ns & $* * *$ & $*$ & $* *$ \\
\hline
\end{tabular}

Chromosome 3

\begin{tabular}{|c|c|c|c|c|}
\hline & \multicolumn{2}{|c|}{$+m$ vs. $m m$} & \multicolumn{2}{|c|}{$\mathrm{MM}$ vs. FF } \\
\hline & $\mathrm{MM}$ & $\mathrm{FF}$ & $+m$ & $\mathrm{~mm}$ \\
\hline$m w h$ & $* * *$ & $* * *$ & ns & ns \\
\hline se & $* * *$ & $* * *$ & $* * *$ & ns \\
\hline th & ns & $* * *$ & $* * *$ & ns \\
\hline$s t$ & $* * *$ & $* * *$ & ns & $* * *$ \\
\hline red & $* * *$ & $* * *$ & $* * *$ & $\mathrm{~ns}$ \\
\hline$e b^{11}$ & ns & $\mathrm{ns}$ & ns & ns \\
\hline $\mathrm{ca}$ & $* * *$ & $* * *$ & $* * *$ & $\mathrm{~ns}$ \\
\hline
\end{tabular}

$\mathrm{ns}=P>0.05$.

$*=0.01<P<0.05$.

$* *=0.001<P<0.01$.

$* * *=P<0.001$.

wild type, even when significantly different from either parental stock (table 1). While very similar results have been obtained for the two sexes in the wild type stock, a variable pattern has been observed in the marker stocks. In general though there is less difference between sexes than between genotypes within sex (table 1).

In order to verify whether the fly length could affect the locomotor activity score, the relationship between this and thorax-abdomen length was analyzed in some of the stocks. In all the cases no significant relationship has been found.

\section{Backcrosses}

Table 2 shows for each marker the number of backcrosses set up and the total number of flies in the sibships analyzed within sex and genotype; midmeans of locomotor activity scores are given in tables 3(a) and 3(b) for all sibships and markers.

With respect to chromosome $\mathrm{X}$ markers, in 53 out of 66 sibships heterozygous females are more active than all their sibs; in 58 sibships heterozygous females are on the average more active than their homozygous sisters, and in 43 families wild
Table 2 Number of backcrosses set up for each marker (NF) and total number of flies tested for each sex and genotype. See also legend to table 1

\begin{tabular}{lccccc}
\hline \multicolumn{2}{l}{ Chromosome X } & & & & \\
\cline { 5 - 6 } & NF & +0 & $+m$ & $m 0$ & $m m$ \\
\hline$w$ & 10 & 181 & 187 & 178 & 163 \\
$c x$ & 11 & 266 & 277 & 194 & 234 \\
$c t^{6}$ & 9 & 170 & 164 & 180 & 157 \\
$t$ & 15 & - & 379 & - & 286 \\
$m$ & 11 & 168 & 195 & 179 & 189 \\
$s d$ & 10 & 138 & 198 & 141 & 164
\end{tabular}

Chromosome 3

\begin{tabular}{|c|c|c|c|c|c|}
\hline & \multirow[b]{2}{*}{ NF } & \multicolumn{2}{|l|}{$+m$} & \multicolumn{2}{|l|}{$m m$} \\
\hline & & $\mathrm{MM}$ & $\mathrm{FF}$ & $\mathbf{M M}$ & $\mathrm{FF}$ \\
\hline$m w h$ & 10 & 205 & 208 & 175 & 181 \\
\hline se & 10 & 172 & 175 & 146 & 143 \\
\hline th & 10 & 162 & 153 & 112 & 129 \\
\hline$s t$ & 10 & 132 & 145 & 143 & 137 \\
\hline red & 10 & 153 & 174 & 161 & 161 \\
\hline$e b^{11}$ & 16 & 268 & 277 & 175 & 193 \\
\hline$c a$ & 9 & 217 & 261 & 129 & 169 \\
\hline
\end{tabular}

type males are more active than their mutant brothers. As far as chromosome 3 is concerned, the heterozygotes show the highest activity independently of sex; in fact which sex is more active seems to depend upon the stock, that is females in $m w h, t h, e b^{11}$ and males in se, st, red, $c t^{6}$ marker stocks.

The first step in the statistical analysis aimed to the detection of linkage between the marker loci and genes affecting locomotor activity was to test the significance of the difference of the average locomotor activity scores between the two segregating classes in the two sexes separately. Midmeans and the significance level of the U-test between genotypes are given in toble 3. Very different patterns are shown in these results, from no significant value (see $e b^{11}$ for males, red and $c a$ for females) to almost all significant values (see se for both sexes). In all the other cases a high variability is seen among sibships for both chromosomes. Jayakar's $I_{2}$ index, which is an estimate of this variability, provides the profiles shown in fig. 5 .

\section{DISCUSSION}

The results of our analyses clearly show that the expression pattern of spontaneous locomotor 
Table 3a Mean locomotor activity score for sex and genotype in each backcross sibship. The significance of U-test for the comparison between genotypes within sex is also shown. See also legend to Table 1

Chromosome $\mathrm{X}$

\begin{tabular}{|c|c|c|c|c|c|c|c|}
\hline \multicolumn{4}{|l|}{ white } & \multicolumn{4}{|l|}{ curlex } \\
\hline+0 & $m 0$ & $+m$ & $m m$ & +0 & $m 0$ & $+m$ & $m m$ \\
\hline $11 \cdot 19$ & $10 \cdot 40$ & $11 \cdot 51$ & $12 \cdot 68$ & $16 \cdot 43$ & $17 \cdot 28$ & $21 \cdot 80$ & $16 \cdot 62^{*}$ \\
\hline $10 \cdot 39$ & $10 \cdot 73$ & $12 \cdot 12$ & $12 \cdot 36$ & $20 \cdot 12$ & $20 \cdot 48$ & $20 \cdot 54$ & $17 \cdot 99^{*}$ \\
\hline $10 \cdot 79^{*}$ & 8.90 & $12 \cdot 59$ & $11 \cdot 50$ & $18 \cdot 63$ & $17 \cdot 23$ & $18 \cdot 62$ & 18.01 \\
\hline $10 \cdot 67$ & $10 \cdot 23$ & $13 \cdot 62$ & $10 \cdot 02^{* *}$ & $19 \cdot 47^{*}$ & $14 \cdot 62$ & $17 \cdot 71$ & $14.99 *$ \\
\hline $11 \cdot 30$ & $10 \cdot 58$ & 15.05 & $10 \cdot 98^{* * *}$ & $15 \cdot 88$ & $17 \cdot 81$ & $18 \cdot 20$ & $16 \cdot 77$ \\
\hline 10.94 & $11 \cdot 67$ & $13 \cdot 79$ & $14 \cdot 01$ & $18 \cdot 14^{* *}$ & $14 \cdot 38$ & $19 \cdot 03$ & $16.03^{* *}$ \\
\hline $11 \cdot 33$ & $10 \cdot 70$ & $14 \cdot 46$ & $11 \cdot 56^{* *}$ & $19 \cdot 36^{*}$ & $16 \cdot 76$ & $19 \cdot 82$ & $16 \cdot 94^{*}$ \\
\hline $11 \cdot 43$ & $10 \cdot 48$ & $12 \cdot 26$ & $12 \cdot 24$ & $18 \cdot 84$ & $17 \cdot 53$ & $21 \cdot 27$ & $18 \cdot 18^{*}$ \\
\hline $12 \cdot 15$ & $10 \cdot 49$ & $14 \cdot 53$ & $11 \cdot 94$ & $19 \cdot 23$ & $17 \cdot 52$ & $21 \cdot 14$ & $21 \cdot 07$ \\
\hline \multirow[t]{2}{*}{$11 \cdot 59$} & $10 \cdot 18$ & $12 \cdot 35$ & $11 \cdot 44$ & $17 \cdot 93$ & $17 \cdot 19$ & $20 \cdot 65$ & $16 \cdot 77^{* *}$ \\
\hline & & & & $17 \cdot 79$ & $16 \cdot 53$ & $17 \cdot 71$ & 18.07 \\
\hline \multicolumn{4}{|l|}{ cut $^{6}$} & \multicolumn{4}{|l|}{$\tan$} \\
\hline+0 & $m 0$ & $+m$ & $m m$ & $+m$ & $m m$ & $+m$ & $m m$ \\
\hline $9 \cdot 42^{* *}$ & $6 \cdot 10$ & 11.95 & $5.93^{* * *}$ & $10 \cdot 18$ & $8 \cdot 20$ & $10 \cdot 20$ & $9 \cdot 90^{*}$ \\
\hline $10 \cdot 44^{* *}$ & $6 \cdot 76$ & $11 \cdot 69$ & $7 \cdot 08^{* *}$ & $12 \cdot 67$ & 10.91 & $9 \cdot 28$ & 8.95 \\
\hline $9 \cdot 82^{* *}$ & $6 \cdot 70$ & $10 \cdot 29$ & $6 \cdot 18^{*}$ & $12 \cdot 86$ & $12 \cdot 72$ & $10 \cdot 77$ & $11 \cdot 14$ \\
\hline $8 \cdot 55$ & $7 \cdot 26$ & $9 \cdot 80$ & $7 \cdot 03^{*}$ & 9.99 & $9 \cdot 82$ & 10.67 & $11 \cdot 40$ \\
\hline $10 \cdot 94^{* * *}$ & $6 \cdot 70$ & $11 \cdot 54$ & $6 \cdot 16^{* *}$ & 13.67 & $10 \cdot 26$ & $10 \cdot 86$ & $11 \cdot 18$ \\
\hline $10 \cdot 83^{*}$ & $7 \cdot 71$ & $12 \cdot 89$ & $7.05^{* *}$ & $11 \cdot 70$ & $11 \cdot 56$ & $13 \cdot 38$ & $12 \cdot 27$ \\
\hline $10 \cdot 76$ & $8 \cdot 36$ & $12 \cdot 13$ & $6 \cdot 74^{* * *}$ & $8 \cdot 20$ & $9 \cdot 94$ & $11 \cdot 62$ & $10 \cdot 52$ \\
\hline $10 \cdot 55^{* *}$ & $5 \cdot 67$ & $11 \cdot 34$ & $8 \cdot 04$ & $13 \cdot 41$ & 12.09 & & \\
\hline $9 \cdot 25$ & $8 \cdot 65$ & $11 \cdot 17$ & $7 \cdot 96^{* *}$ & & & & \\
\hline \multicolumn{4}{|l|}{ miniature } & \multicolumn{4}{|c|}{ scalloped } \\
\hline+0 & $\mathrm{~m} 0$ & $+\mathrm{m}$ & $\mathrm{mm}$ & +0 & $\mathrm{~m} 0$ & $+\mathrm{m}$ & $\mathrm{mm}$ \\
\hline $12 \cdot 00^{* *}$ & $9 \cdot 24$ & $12 \cdot 86$ & $10 \cdot 06$ & $8 \cdot 91$ & $8 \cdot 37$ & $9 \cdot 20$ & $7 \cdot 20$ \\
\hline $10 \cdot 46$ & $7 \cdot 82$ & $13 \cdot 85$ & $8 \cdot 38^{* *}$ & $12 \cdot 07^{*}$ & $9 \cdot 56$ & $14 \cdot 40$ & $11 \cdot 34$ \\
\hline $12 \cdot 36^{*}$ & $9 \cdot 34$ & $12 \cdot 37$ & $9 \cdot 01^{* *}$ & $10 \cdot 87$ & $10 \cdot 52$ & $13 \cdot 81$ & $9 \cdot 30^{*}$ \\
\hline $9 \cdot 76$ & $8 \cdot 16$ & $11 \cdot 07$ & $9 \cdot 56$ & $10 \cdot 14$ & $9 \cdot 98$ & $11 \cdot 82$ & $11 \cdot 53$ \\
\hline $10 \cdot 28$ & $6 \cdot 13$ & 14.45 & $10 \cdot 43$ & 8.00 & $8 \cdot 35$ & $10 \cdot 43$ & $7 \cdot 90$ \\
\hline $14.48^{*}$ & $9 \cdot 32$ & $14 \cdot 17$ & $8 \cdot 15^{* * *}$ & $9 \cdot 50$ & $7 \cdot 12$ & $12 \cdot 51$ & $9 \cdot 58$ \\
\hline $12 \cdot 53^{* * *}$ & $6 \cdot 76$ & $13 \cdot 17$ & $8 \cdot 52 * * *$ & $12 \cdot 15$ & $9 \cdot 37$ & $13 \cdot 48$ & $12 \cdot 04$ \\
\hline $13 \cdot 20$ & $10 \cdot 57$ & $13 \cdot 85$ & $11 \cdot 59^{* *}$ & $11 \cdot 11$ & $9 \cdot 86$ & $13 \cdot 35$ & $10 \cdot 90$ \\
\hline $11 \cdot 53^{*}$ & $9 \cdot 24$ & $11 \cdot 61$ & $9 \cdot 35$ & $10 \cdot 28$ & 8.47 & $11 \cdot 04$ & 10.01 \\
\hline $13 \cdot 35^{* * *}$ & $8 \cdot 34$ & 13.09 & $9.94^{* *}$ & $10 \cdot 74^{*}$ & $8 \cdot 17$ & $10 \cdot 51$ & $6.03^{* *}$ \\
\hline $13 \cdot 06 * *$ & $9 \cdot 41$ & $12 \cdot 22$ & $12 \cdot 03$ & & & & \\
\hline
\end{tabular}

activity differs from stock to stock. Noteworthy is also the clustered distribution of null-activity individuals observed among the marker stocks. The above remarks suggest that quite a lot of genetic variability exists among marker stocks for the control of locomotor activity, which is not surprising because of their different historical origins: in fact the stocks we have used come from different laboratories, and may be characterized by different arrangements of alleles for the genes affecting locomotion. The higher locomotor activity generally shown by the $m /+$ heterozygotes, which are in fact hybrids of two different stocks, could be explained by the fact that crosses between individuals from a marker stock and wild Cast-PD may yield increased genetic variability accompanied by positive effects on locomotion.

Previous findings (van Dijken et al., 1979; Burnet et al., 1988) suggesting a clear influence on locomotor activity exerted by chromosome $\mathrm{X}$ are confirmed by our results, since significant differences in activity between sexes within the same genotype have been observed for chromosome 3 markers, with the exception of $e b^{11}$. 
Table 3b Mean locomotor activity score for sex and genotype in each backcross sibship. The significance of U-test for the comparison between genotypes within sex is also shown. See also legend to Table 1

Chromosome 3

multiple wing hair

\begin{tabular}{|c|c|c|c|c|c|c|c|}
\hline \multicolumn{2}{|l|}{ MM } & \multicolumn{2}{|l|}{$\mathrm{FF}$} & \multicolumn{2}{|l|}{ MM } & \multicolumn{2}{|l|}{$\mathrm{FF}$} \\
\hline$+m$ & $\mathrm{~mm}$ & $+m$ & $\mathrm{~mm}$ & $+m$ & $m m$ & $+m$ & $\mathrm{~mm}$ \\
\hline $5 \cdot 44$ & $5 \cdot 14$ & $10 \cdot 68$ & $5 \cdot 77^{* * * *}$ & $17 \cdot 39^{*}$ & $14 \cdot 84$ & $17 \cdot 01$ & $14 \cdot 26^{* * *}$ \\
\hline 6.48 & $7 \cdot 59$ & $11 \cdot 03$ & $6 \cdot 28 *$ & $19 \cdot 62^{* * *}$ & $15 \cdot 64$ & $17 \cdot 60$ & $14-75^{* * *}$ \\
\hline $8 \cdot 54$ & $5 \cdot 89$ & $8 \cdot 66$ & $5 \cdot 09^{* *}$ & $18 \cdot 36^{* * *}$ & $15 \cdot 40$ & $16 \cdot 32$ & $14 \cdot 37^{* *}$ \\
\hline $7 \cdot 72$ & 4.93 & $6 \cdot 01$ & $4 \cdot 20$ & $16.99^{* *}$ & $15 \cdot 09$ & $16 \cdot 98$ & $14 \cdot 52^{* * *}$ \\
\hline $8.03^{*}$ & $5 \cdot 79$ & 8.84 & $4 \cdot 69^{* *}$ & 17.92 & $17 \cdot 56$ & $15 \cdot 74$ & $13 \cdot 94$ \\
\hline $9 \cdot 65$ & 6.90 & $8 \cdot 61$ & $6 \cdot 18^{*}$ & $20 \cdot 80^{* * *}$ & $15 \cdot 17$ & $16 \cdot 78$ & $13 \cdot 47^{* * *}$ \\
\hline $9 \cdot 42^{* *}$ & $4 \cdot 58$ & $9 \cdot 67$ & $6.83^{*}$ & $19 \cdot 58^{* * *}$ & $13 \cdot 72$ & $16 \cdot 51$ & $13 \cdot 95^{* * *}$ \\
\hline 8.00 & $5 \cdot 82$ & $8 \cdot 48$ & $4 \cdot 32^{* * *}$ & $18 \cdot 51 * * *$ & $14 \cdot 02$ & $17 \cdot 05$ & $14 \cdot 34^{* * *}$ \\
\hline 6.41 & $3 \cdot 78$ & $7 \cdot 61$ & $5 \cdot 65$ & $19 \cdot 04^{* * *}$ & $14 \cdot 45$ & $16 \cdot 84$ & $15.09 * * *$ \\
\hline $6 \cdot 10$ & $6 \cdot 21$ & $6 \cdot 36$ & $6 \cdot 38$ & $19 \cdot 52^{* * *}$ & $14 \cdot 72$ & $14 \cdot 74$ & $15 \cdot 15^{* *}$ \\
\hline \multicolumn{4}{|l|}{ thread } & \multicolumn{4}{|l|}{ scarlet } \\
\hline MM & & FF & & MM & & FF & \\
\hline$+m$ & $m m$ & $+m$ & $m m$ & $+m$ & $m m$ & $+m$ & $m m$ \\
\hline $12 \cdot 43$ & $11 \cdot 60$ & $15: 32$ & $10 \cdot 43$ & $16 \cdot 35$ & $15 \cdot 56$ & $16 \cdot 17$ & $14 \cdot 52$ \\
\hline $12 \cdot 90$ & $11 \cdot 79$ & $13 \cdot 56$ & $13 \cdot 11$ & $17 \cdot 95^{*}$ & $16 \cdot 18$ & $13 \cdot 65$ & $14 \cdot 79$ \\
\hline $10 \cdot 30$ & $9 \cdot 40$ & $13 \cdot 16$ & $10 \cdot 98^{* *}$ & $15 \cdot 79$ & $17 \cdot 16$ & $16 \cdot 40$ & $15 \cdot 30$ \\
\hline $12 \cdot 44^{* * *}$ & $8 \cdot 43$ & $14 \cdot 85$ & $10 \cdot 31^{* * *}$ & $17 \cdot 50$ & $16 \cdot 75$ & $16 \cdot 46$ & $14 \cdot 13^{* *}$ \\
\hline $15 \cdot 43^{*}$ & $10 \cdot 60$ & $14 \cdot 20$ & $13 \cdot 96$ & $17 \cdot 73$ & $16 \cdot 40$ & $17 \cdot 50$ & $15 \cdot 88^{* * *}$ \\
\hline $11 \cdot 16$ & $11 \cdot 78$ & $15 \cdot 03$ & $14 \cdot 03$ & $18 \cdot 84^{*}$ & $16 \cdot 20$ & $17 \cdot 76$ & $15 \cdot 16$ \\
\hline $11 \cdot 71^{*}$ & $9 \cdot 04$ & $12 \cdot 76$ & $9 \cdot 42^{*}$ & $17 \cdot 70^{*}$ & $15 \cdot 36$ & $17 \cdot 62$ & $15 \cdot 57^{*}$ \\
\hline $12 \cdot 32^{* * *}$ & $9 \cdot 57$ & $14 \cdot 43$ & $10 \cdot 47 * * *$ & $17 \cdot 20$ & $15 \cdot 64$ & $17 \cdot 07$ & $15 \cdot 15^{*}$ \\
\hline $9 \cdot 83$ & $9 \cdot 33$ & $13 \cdot 24$ & $12 \cdot 48$ & $18 \cdot 09$ & $16 \cdot 78$ & $17 \cdot 66$ & $16 \cdot 47$ \\
\hline $13 \cdot 26$ & $8 \cdot 70$ & $13 \cdot 54$ & $13 \cdot 54$ & $17 \cdot 86$ & $17 \cdot 86$ & $16 \cdot 17$ & $14 \cdot 68$ \\
\hline
\end{tabular}

ebony $^{11}$

\begin{tabular}{|c|c|c|c|c|c|c|c|}
\hline \multicolumn{2}{|l|}{$\mathrm{MM}$} & \multicolumn{2}{|l|}{$\mathrm{FF}$} & \multicolumn{2}{|l|}{$\mathrm{MM}$} & \multicolumn{2}{|l|}{ FF } \\
\hline$+m$ & $m m$ & $+m$ & $m m$ & $+m$ & $m m$ & $+m$ & $m m$ \\
\hline $9 \cdot 04$ & $9 \cdot 37$ & $10 \cdot 10$ & $10 \cdot 24$ & $10 \cdot 86$ & $9 \cdot 72$ & $11 \cdot 82$ & $11 \cdot 56$ \\
\hline $9 \cdot 38$ & $8 \cdot 48$ & $10 \cdot 25$ & $9 \cdot 12$ & $8 \cdot 48$ & $7 \cdot 81$ & $10 \cdot 43$ & $7 \cdot 24^{* *}$ \\
\hline $10 \cdot 20$ & $9 \cdot 56$ & $11 \cdot 62$ & $8 \cdot 87^{* *}$ & $9 \cdot 47$ & $9 \cdot 05$ & $11 \cdot 10$ & $10 \cdot 23$ \\
\hline $9 \cdot 85$ & $8 \cdot 74$ & $10 \cdot 68$ & $9 \cdot 58$ & $9 \cdot 47$ & $8 \cdot 99$ & $10 \cdot 45$ & 9.74 \\
\hline $8 \cdot 51$ & $8 \cdot 71$ & $9 \cdot 25$ & $9 \cdot 04$ & $6 \cdot 60$ & $9 \cdot 85$ & $10 \cdot 77$ & $9 \cdot 11$ \\
\hline 9.59 & $9 \cdot 42$ & $10 \cdot 10$ & $9 \cdot 36$ & $9 \cdot 35$ & 9.86 & $10 \cdot 67$ & $11 \cdot 20$ \\
\hline $8 \cdot 72$ & $9 \cdot 82$ & 10.77 & $9 \cdot 89$ & $9 \cdot 49$ & $9 \cdot 54$ & $9 \cdot 70$ & $10 \cdot 15$ \\
\hline $9 \cdot 35$ & $8 \cdot 10$ & 8.48 & $9 \cdot 10$ & $8 \cdot 64$ & $8 \cdot 21$ & $9 \cdot 50$ & $10 \cdot 18$ \\
\hline \multicolumn{4}{|l|}{ red } & \multicolumn{4}{|l|}{ claret } \\
\hline \multicolumn{2}{|l|}{$\mathbf{M M}$} & \multicolumn{2}{|l|}{$\mathrm{FF}$} & \multicolumn{2}{|l|}{$\mathrm{MM}$} & \multicolumn{2}{|l|}{$\mathrm{FF}$} \\
\hline$+m$ & $m m$ & $+m$ & $\mathrm{~mm}$ & $+m$ & $m m$ & $+m$ & $m m$ \\
\hline $17 \cdot 81$ & $20 \cdot 34$ & $15 \cdot 82$ & $15 \cdot 60$ & $14 \cdot 23$ & $13 \cdot 29$ & $13 \cdot 62$ & $12 \cdot 22$ \\
\hline $18 \cdot 93$ & $18 \cdot 14$ & $15 \cdot 21$ & $14 \cdot 82$ & $12 \cdot 80$ & $11 \cdot 58$ & $12 \cdot 71$ & $11 \cdot 01$ \\
\hline $16 \cdot 42$ & $14 \cdot 98$ & $14 \cdot 47$ & $15 \cdot 34$ & $13 \cdot 80$ & $13 \cdot 61$ & $13 \cdot 73$ & $13 \cdot 56$ \\
\hline $18 \cdot 45$ & $16 \cdot 05$ & $16 \cdot 53$ & $15 \cdot 12$ & $13 \cdot 19$ & $13 \cdot 17$ & $12 \cdot 82$ & $14 \cdot 27$ \\
\hline $19.59^{*}$ & $16 \cdot 26$ & $15 \cdot 34$ & $15 \cdot 23$ & $15 \cdot 50$ & $16 \cdot 17$ & $14 \cdot 76$ & $15 \cdot 27$ \\
\hline $18.98^{* * *}$ & $15 \cdot 49$ & $14 \cdot 48$ & $14 \cdot 42$ & $13 \cdot 70$ & $14 \cdot 47$ & $13 \cdot 27$ & $13 \cdot 89$ \\
\hline $19 \cdot 02^{* * *}$ & $15 \cdot 32$ & $14 \cdot 74$ & $13 \cdot 05$ & $13 \cdot 25^{*}$ & $15 \cdot 11$ & $13 \cdot 61$ & $13 \cdot 62$ \\
\hline $17 \cdot 04$ & $16 \cdot 82$ & $15 \cdot 79$ & $14 \cdot 59$ & $13 \cdot 33$ & $12 \cdot 20$ & $12 \cdot 25$ & $12 \cdot 28$ \\
\hline $17 \cdot 48$ & $17 \cdot 31$ & $15 \cdot 22$ & $14 \cdot 77$ & $14 \cdot 60$ & $14 \cdot 04$ & $13 \cdot 03$ & $12 \cdot 52$ \\
\hline $17 \cdot 58$ & $17 \cdot 78$ & $15 \cdot 72$ & $15 \cdot 85$ & & & & \\
\hline
\end{tabular}



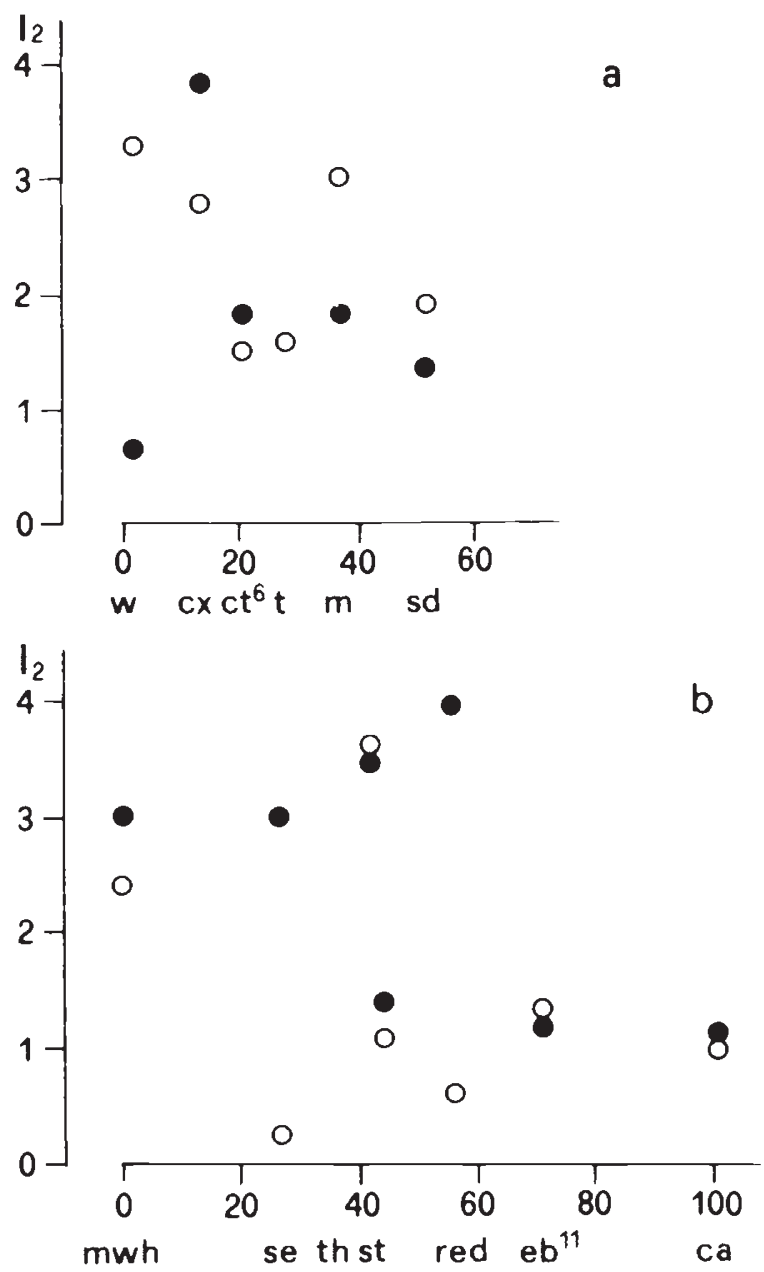

Figure $5 I_{2}$ index values are shown according to the chromosome map separately for the two sexes (males; $O$ females). a, chromosome X; b, chromosome 3 .

Considering the results of backcross experiments, the tendency towards higher locomotor activity shown by almost all of the $m /+$ heterozygotes, only for females in the case of sex linked markers, suggests that the chromosomal region carrying the genetic marker does affect locomotion. As a matter of fact, a common randomized genetic background is expected in the $\mathrm{m} /+$ and $\mathrm{m} / \mathrm{m}$ individuals of a sibship, so that the differences in the expression of the quantitative character are likely to be due either to the marker locus itself or to genes tightly linked to it. Unfortunately, the greater differences in the genetic background between $+/ m$ and $m / m$ controls prevented us from applying a correction for the effect of the marker locus of the type $\left(\mathrm{x}_{1}-\mathrm{x}_{2}\right)-\left(\mathrm{x}_{\mathrm{cl}}-\mathrm{x}_{\mathrm{c} 2}\right)$-where $\mathrm{x}_{1}$ and $x_{2}$ are the means of the two segregating classes and $x_{\mathrm{c} 1}$ and $x_{\mathrm{c} 2}$ are the means of the controls of the corresponding genotypes-suggested by the experimental scheme of fig. 2 (Jayakar et al., 1977). According to Jayakar's model, only the whole set of comparisons for several sibships of a marker may be informative on the presence of linkage between this marker locus and a "quantitative" gene. The heterogeneity of the U-test values among sibships (tables 3(a) and 3(b)) for the different markers indicate that several genes influencing locomotor activity are present on both chromosomes. Jayakar's $I_{2}$ index has been applied as an estimate of the variability among sibships, since it reveals the presence of linkage from the variance among sibships of the difference of the trait means of the segregating classes within sibship. The $I_{2}$ values calculated for all markers have then been mapped along the two chromosomes. The $I_{2}$ profiles we have obtained for both chromosomes $X$ and 3 are quite complex and once more suggest the presence of several genes affecting locomotor activity on both chromosomes. Furthermore, because the value of $I_{2}$ depends also on the parameters $F_{1}$ and $F_{2}$ which can differ in the different marker stocks, a univocal interpretation of the linkage map is not possible. An improvement in the experimental approach could be achieved using enzymatic or restriction fragment length polymorphisms rather than morphological markers. The overall $I_{2}$ picture suggests that there should be at least one locus significantly affecting adult locomotor activity near to each marker locus tested. It is not particularly surprising that a very complex quantitative trait as adult locomotor activity could be affected by at least a dozen major genes distributed on different chromosomes. As for which chromosomes are involved, our results are consistent with those of van Dijken et al. (1979) and Burnet et al. (1988). Our measure of locomotor activity does not discriminate between amount of locomotion and speed, but since Burnet et al. (1988) demonstrated significant effects of chromosome 3 on the former component and of chromosomes $\mathrm{X}$ and 2 on the latter, it is likely that some of the major genes affecting locomotor activity detected by our analysis influence specifically one of the above components.

Differences at the biochemical levels have been hypothesized to account for different levels of locomotor activity in strains of $D$. melanogaster selected for different values of this character. van Dijken et al. (1979) found differences in NADH dehydrogenase activity between high and low locomotor activity lines. Tuncliff et al. (1969) found 
a significant influence on locomotion of dopamine and noradrenaline levels, implying that a control can be exerted by the balance existing between the two; on the contrary, he did not detect significant differences in serotonin levels and cholinesterase activity. More recently, Meehan and Wilson (1987) studying the dopamine-deficient Tyr-1 mutant, and giving separate measures for different components of locomotor activity, demonstrated that Tyr-1 flies have "normal" levels of spontaneous activity or reactivity but higher levels of "stimulated activity". It seems interesting to note that some of the morphological markers we used are linked to loci coding for enzymes playing a relevant role in the energetic metabolism of the flies and known to be polymorphic in the wild. This is the case of $w$ linked to $P g d$, of $c t^{6}$ linked to Fum, of se linked to $I d h$, of th and st linked to Pgm, of red linked to Ace, of ca linked to Tpi. Nevertheless whether or not the above biochemical loci are really involved in significantly influencing locomotor activity remains at the moment merely a fascinating hypothesis.

Acknowledgements We wish to thank Mrs S. Zanoli for technical help. This work was supported by MPI 40 per cent "Ecological Genetics" National Group.

\section{REFERENCES}

ANGUS, J. 1974. Genetic control of activity, preening, and the response to a shadow stimulus in Drosophila melanogaster. Behav. Genet., 4, 317-329.

BECKMANN, J. S. ANI SOLLER, M. 1983. Restriction fragment length polymorphism in genetic improvement methodologies, mapping and costs. Theor. Appl. Genet., $67,35-43$.

BURNET, B. ANI CONNOLLY, K. 1974. Activity and sexual behaviour in Drosophila melanogaster. In Abeelen, J. H. F. van (ed.) The Genetics of Behaviour, North-Holland Publishing Company, Amsterdam, Oxford, pp. 201-258.

BURNET, B., BURNET, L., CONNOLLY, K. AND WILLIAMSON, N. 1988. A genetic analysis of locomotor activity in Drosophila melanogaster. Heredity, 61, 111-119.

CONNOLLY, K. 1966. Locomotor activity in Drosophila. II. Selection for active and inactive strains. Anim. Behav., 14, 444 449 .

CONNOLLY, K. 1967. Locomotor activity in Drosophila. III. A distinction between activity and reactivity. Anim. Behav, 15, 149-152.

CHOTAI, J. 1984. On the lod score method in linkage analysis. Ann. Hum. Genet., 48, 359-378.

DIJKEN, F. R. VAN AND SCHARLOO, W. 1979a. Divergent selection on locomotor activity in Drosophila melanogaster. I. Selection response. Behav. Genet., 9, 543-553.

DIJKEN, F. R. VAN AND SCHARLOO, w. 1979b. Divergent selection on locomotor activity in Drosophila melanogaster. II. Test for reproductive isolation between selected lines. Behav. Genet., 9, 555-561.
DIJKEN, F. R. VAN, SAMBEEK, M. P. J. W. VAN AND SCHARLOO, W. 1979. Divergent selection on locomotor activity in Drosophila melanogaster. III. Genetic analysis. Behav. Genet., 9, 563-570.

DIJKEN, F. R. VAN, STOLWIJK, H. AND SCHARLOO, W. 1977. Locomotor activity in Drosophila melanogaster. Neth. J. Zool., 35, 438-454.

EWING, A. W. 1963. Attempts to select for spontaneous activity in Drosophila melanogaster. Anim. Behav., 11, 369-378.

HILL, A. P. 1975. Quantitative linkage: a statistical procedure for its detection and estimation. Ann. Hum. Genet., 38, 439-450.

JAYAKAR, S. D. 1970 . On the detection and estimation of linkage between a locus influencing a quantitative character and a marker locus. Biometrics, 26, 451-464.

JAYAKAR, S. D., DELLA CROCE, L., SCACCHI, M. AND GUAZZOTT!, G. 1977. A genetic linkage study of a quantitative trait in Drosophila melanogaster. Proc. Internat. Conf. on Quantitative Genetics, lowa State University Press, Ames, Iowa, pp 161-175.

KYRIACOU, C. P. 1981. The relationship between locomotor activity and sexual behaviour in ebony strains of Drosophila melanogaster. Anim. Behav., 29, 462-471.

LE BOURG, E. AND LINTS, F. A. 1984. A longitudinal study of the effects of age on spontaneous locomotor activity in Drosophila melanogaster. Gerontology, 30, 79-86.

LF. BOURG, E., LINTS, F. A. AND LINTS, C. V. 1984. Does a relationship exist between spontaneous locomotor activity, fitness and lifespan in Drosophila melanogaster? Exp. Geront., 19, 205-210.

LINDSLEY, D. L. AND GRELL, E. H. 1972. Genetic variations of Drosophila melanogaster, Carnegie Inst. of Wash. Publ. $627,1-471$.

LINTS, F. A., LE BOURG, E. ANI LINTS, C. V. 1984. Spontaneous locomotor activity and lifespan: a test of the rate of living theory in Drosophila melanogaster. Gerontology, 30, 376387.

LINTS, F. A., LE BOURG, E. ANI LINTS, C. V. 1985. An attempt to select for spontaneous locomotor activity in Drosophila melanogaster. Behav. Proc., 11, 97-102.

MARONI, G., LAURIE-AHLBERG, C. C., ADAMS, A. D. AND WILTON, A. N. 1982. Genetic variation in the expression of ADH in Drosophila melanogaster. Genetics, 101, 431446.

MEEHAN, M. J. AND WILSON, R. 1987. Locomotor activity in the Tyr-1 mutant of Drosophila melanogaster. Behav. Genet., 17, 503-512.

MITTLER, S. AND BENNET, J. 1962. A simple food medium that requires no live yeast with a minimum of variables. Drosophila Inform. Serv., 36, 131-132.

O'DELL, K. AND BURNET, B. 1988. The effects on locomotor activity and reactivity of the hypoactive and inactive mutations of Drosophila melanogaster. Heredity, 61, 199-207.

SCHNEF, F. B. AND THOMPSON, JR., J. N. 1984. Conditional polygenic effects in the sternopleural bristle system of Drosophila melanogaster. Genetics, 118, 437-443.

SEWELL, D., BURNET, B. AND CONNOLLY, K. 1975. Genetic analysis of larval feeding behaviour in Drosophila melanogaster. Genet. Res. Camb., 24, 163-173.

SHRIMPTON, A. E. AND ROBERTSON, A. 1988a. The isolation of polygenic factors controlling bristle score in Drosophila melanogaster. 1. Allocation of third chromosome sternopleural bristle effects to chromosome sections. Genetics, $118,437-443$.

SHRIMPTON, A. F. AND ROBERTSON, A. 1988b. The isolation of polygenic factors controlling bristle score in Drosophila melanogaster. II. Distribution of third chromosome bristle effects within chromosome sections. Genetics, 118, 445-459. 
TANKSLEY, S. D., MEDINA-FILHO, H. AND RICK, C. M. 1982. Use of naturally occurring enzyme variation to detect and map genes controlling quantitative traits in an interspecific backcross of tomato. Heredity, 49, 11-25.

THODAY, J. M. 1961. Location of polygenes. Nature, 191, $368-$ 370.

THODAY, J. M. 1966. New insights into continuous variation. In Proc. Third Int. Cong. Hum. Genet.

THOMPSON, J. N., JR. AND THODAY, J. M. 1979. Quantitative Genetic Variation. Academic Press, London.

THOMPSON, J. N., SCHNEE, F. B. AND SEALE, T. W. 1983. Polygenic analysis of larval locomotor activity in Drosophila melanogaster. Behav. Genet., 13, 579 589.

TUKEY, J. W. 1977. Exploratory data analysis. Addison Wesley Publ. Comp.

TUNNICLIFF, G., RICK, J. T. AND CONNOLLY, K. 1969. Locomotor activity in Drosophila. V. A comparative biochemical study of selectively bred populations. Comp. Biochem. Physiol., 29, 1239-1245.
VAJ, E. AND JAYAKAR, S. D. 1976. Genetic studies on locomotor activity in Drosophila. Atti Ass. Genet. It., 21, 208-210.

VALlEJOS, C. E. AND TANKSLEY, S. D. 1983. Segregation of isozymes markers and cold tolerance in an interspecific backcross of tomato. Theor. Appl. Genet., 66, 241-247.

WELLER, J. I. 1986. Maximum likelihood techniques for the mapping and analysis of quantitative trait loci with the aid of genetic markers. Biometrics, 42, 627-641.

WELLER, J. I. 1987. Mapping and analysis of quantitative trait loci in Lycopersicon (tomato) with the aid of genetic markers using approximate maximum likelihood methods. Heredity, 59, 413-421.

WELLER, J. I., SOLLER, M. AND BRODY, T. 1988. Linkage analysis of quantitative traits in an interspecific cross of tomato (L. esculentum $\times$ L. pimpinellifolium) by means of genetic markers. Genetics, 118, 329-339. 